that the error in $D^{*}$ from this source is, at the most, twice that which occurs in $C^{*}$.

The remaining source of error is that due to the truncation of the series from which $D_{3}{ }^{*}$ was calculated. We estimate the uncertainty due to this truncation, probably conservatively, as equal in magnitude to the last term included, i.e., the fourth term. For temperatures above $T^{*}=2.0$ this is entirely negligible.

Taking all contributions into consideration we arrive at the conservative estimates of uncertainty given in Table IX.

\section{DISCUSSION}

We have checked our method for calculating fourth virial coefficients by comparing the results obtained for square-well potentials with those obtained by an entirely different method, and found good agreement. We have made calculations for the Lennard-Jones 12-6 potential, and formed estimates of error which indicate that our method gives reasonably accurate values for the fourth virial coefficient for this potential when the reduced temperature is greater than 1.2. For low reduced temperatures our values are up to $40 \%$ smaller than those of Boys and Shavitt, but at higher reduced temperatures our results agree well with theirs.
We do not propose to make detailed comparisons with experiments at present since this is an extensive task in itself. However, there is one comparison which can be made readily, namely the determination of the critical constants. If we assume that the fifth and higher virial coefficients can be neglected we find that the conditions for the critical point are satisfied when $k T / \epsilon$ is $1.30, P \sigma^{3} / \epsilon$ is 0.122 and $V / N \sigma^{3}$ is 3.7. In Table $\mathrm{X}$ we compare these quantities with experimental values for argon based on the parameters $\sigma=3.405 \mathrm{~A}$, $\epsilon / k=119.8^{\circ} \mathrm{K}$ derived by Michels et al. ${ }^{6}$ from measurements of second virial coefficients.

The agreement with respect to critical temperature and pressure is good. For the critical volume the agreement is less satisfactory, the theoretical and experimental values differing by $15 \%$. Because of the nature of the critical isotherm the critical volume is particularly sensitive to small contributions from higher virial coefficients. Thus the results in Table $\mathrm{X}$ may be taken as an indication that the potential function for the interaction between argon atoms is probably not very different from the 12-6 function.

${ }^{6}$ A. Michels, Hub. Wijker, and Hk. Wijker, Physica 15, 627 (1949).

\title{
Thermal Properties Based upon Heat Capacity and Decomposition Pressure of Tetramethylammonium Hydrogen Dichloride. Nature of the Hydrogen Bond in the $[\mathrm{Cl}-\mathrm{H}-\mathrm{Cl}]^{-}$Ion*
}

\author{
Shu-Sing Chang and Edgar F. Westrum, Jr. \\ Depariment of Chemistry, University of Michigan, Ann Arbor, Michigan
}

(Received November 22, 1961)

\begin{abstract}
The heat capacity of tetramethylammonium hydrogen dichloride was determined from $5^{\circ}$ to $350^{\circ} \mathrm{K}$ by adiabatic calorimetry and the derived thermodynamic properties were calculated. No thermal anomalies were found. Molal values of heat capacity, entropy, and free-energy function at $298.15^{\circ} \mathrm{K}$ are $49.07,60.63$, and $-31.72 \mathrm{cal} \mathrm{mole}{ }^{-1}{ }^{\circ} \mathrm{K}^{-1}$, respectively. The decomposition pressure of tetramethylammonium hydrogen dichloride, measured from $340^{\circ}$ to $380^{\circ} \mathrm{K}$ with a Bourdon gauge as the null indicator, can be represented by the equation $\log _{10} P_{\mathrm{mm}}=-28.4677-1698.5 T^{-1}+15.502 \log _{10} T-0.012256 T$. Extrapolated values at $298.15^{\circ}$ and $410.8^{\circ} \mathrm{K}$ are 1.8 and $760 \mathrm{~mm} \mathrm{Hg}$, respectively. Entropy increments for the decomposition reaction were calculated from the equilibrium data and compared with third-law entropy increment values derived from the thermal data. Excellent agreement was obtained. This provides strong support for the location of the equilibrium position of the hydrogen ion midway between the two chloride ions.
\end{abstract}

\section{INTRODUCTION}

$\mathbf{T}$ HE fact that the proton in the hydrogen difluoride ion in the alkali-metal hydrogen difluorides is situated in a single minimum potential-energy well midway between the two fluoride ions has now been widely recognized. Evidence for the existence of such a symmetrical hydrogen difluoride ion has been provided

* This work was supported by the Division of Research of the U. S. Atomic Energy Commission and was presented in partial fulfillment for the requirements of the Ph.D. at the University of Michigan by S. S. C. by evaluation of the heat capacity, ${ }^{1}$ the residual entropy, ${ }^{2,3}$ studies of infrared spectroscopy, ${ }^{4}$ Raman

\footnotetext{
${ }^{1}$ K. S. Pitzer and E. F. Westrum, Jr., J. Chem. Phys. 15, 526 (1947).

${ }^{2}$ E. F. Westrum, Jr. and K. S. Pitzer, J. Am. Chem. Soc. 71, 1940 (1949).

${ }^{3}$ M. L. Davis and E. F. Westrum, Jr., J. Phys. Chem. 65, 338 (1961).

${ }^{4}$ J. A. A. Ketelaar, J. Chem. Phys. 9, 775 (1941); Rec. trav. chim. 60, 523 (1941); J. A. A. Ketelaar and W. Vedder, J. Chem. Phys. 19, 654 (1951); R. Newman and R. M. Badger, ibid. 19, 1207 (1951).
} 
spectroscopy, ${ }^{5}$ neutron diffraction, ${ }^{6}$ and nuclear magnetic resonance ${ }^{7}$ on potassium hydrogen difluoride. The hydrogen difluoride ion contains the strongest hydrogen bond known. With the hydrogen atom in the middle of two fluoride ions, the hydrogen atom may be considered to form a half bond with each of the fluoride ions and have a bond number corresponding to that of the bridge hydrogen atoms in boranes. ${ }^{8}$

Waddington ${ }^{9}$ suggested, upon examination of the infrared spectrum of tetramethylammonium hydrogen dichloride, that its hydrogen dichloride ion $^{10}$ $[\mathrm{Cl}-\mathrm{H}-\mathrm{Cl}]$, might be another example of symmetrical hydrogen bonding. It is the purpose of this work to establish the evidence for the symmetry of the hydrogen dichloride ion through entropy evaluations and construction of a third-law cycle for the reaction

$$
\left(\mathrm{CH}_{3}\right)_{4} \mathrm{NHCl}_{2(\mathrm{~s})}=\left(\mathrm{CH}_{3}\right)_{4} \mathrm{NCl}_{(\mathrm{s})}+\mathrm{HCl}_{(\mathrm{g})} \text {. }
$$

The entropy increment of the reaction derived from direct equilibrium constant measurements is compared with the entropy increment determined from the third law of thermodynamics using low-temperature heatcapacity measurements on tetramethylammonium chloride and on tetramethylammonium hydrogen dichloride together with statistically calculated entropy values for gaseous hydrogen chloride from spectroscopic data.

If the substances involved in the reaction are perfectly ordered crystals at low temperatures and hence have no residual entropy, and there are no solid solutions in the system, the two values derived from direct equilibrium measurement and from third-law evaluation should agree with each other. However if the hydrogen is not centrally situated in symmetrically located $[\mathrm{Cl}-\mathrm{H}-\mathrm{Cl}]-$ ions, then a disordered structure would be expected for tetramethylammonium hydrogen dichloride at low temperatures with a consequent residual entropy of $R \ln 2$. In this case, the value obtained from third-law entropies for the above mentioned reaction would be about $R \ln 2=1.38 \mathrm{cal} \mathrm{mole}{ }^{-1}{ }^{\circ} \mathrm{K}^{-1}$ higher than that obtained from decomposition pressure measurement.

\section{EXPERIMENTAL}

\section{Preparation of Sample}

Tetramethylammonium dichloride is customarily prepared by passing dry hydrogen chloride over tetramethylammonium chloride or by condensing the gas on

${ }^{5} \mathrm{~L}$. A. Woodward and H. J. Tyrell, Trans. Faraday Soc. 38, 513 (1942).

${ }^{6}$ S. W. Peterson and H. A. Levy, J. Chem. Phys. 20, 704 (1952).

${ }^{7}$ J. S. Waugh, F. B. Humphrey, and D. M. Yost, J. Phys. Chem. 57, 486 (1953).

${ }^{8} \mathrm{~L}$. Pauling, The Nature of the Chemical Bond (Cornell University Press, Ithaca, New York, 1960), 3rd ed.

$\circ$ T. C. Waddington, J. Chem. Soc. 1958, 1708.

${ }^{10} \mathrm{H}$. F. Herbrandson, R. T. Dickerson, Jr., and J. Weinstein, J. Am. Chem. Soc. 76, 4046 (1954). the solid neutral salt. ${ }^{9,11}$ With the aid of a vacuum line, gaseous hydrogen chloride from the Matheson Company was first passed through a trap cooled in a bath of a mixture of dry ice and denatured alcohol and then condensed into a container at liquid-nitrogen temperature. After a sufficient amount of hydrogen chloride had been collected, a $\mathrm{CS}_{2}$ slush bath replaced the liquid-nitrogen bath and hydrogen chloride was then distilled at this temperature, $-111^{\circ} \mathrm{C}$, into containers cooled by liquid nitrogen. The first and the last fractions were discarded. The middle portion was again distilled into a bulb containing about $30 \mathrm{~g}$ of purified tetramethylammonium chloride prepared as described previously. ${ }^{12}$ The temperature of the reaction flask was alternated frequently between that of the carbon disulfide slush bath and that of a dry ice and alcohol mixture (and even occasionally that of a liquid-nitrogen bath) thereby stirring the mixture of tetramethylammonium chloride and liquid hydrogen chloride rather effectively until finally a completely clear solution was obtained. Excess hydrogen chloride was then allowed to distill out slowly at the temperature of a carbon disulfide slush bath.

The sample thus obtained was in the form of brittle polycrystalline powder. The weight of hydrogen chloride absorbed by tetramethylammonium chloride was checked by a solution balance. Acidimetric titration indicated the content of $\mathrm{HCl}$ in the sample to be $24.88 \%$ by weight (theoretical: $24.96 \%$ ). Hence, the sample was composed of $99.20 \%$ of $\left(\mathrm{CH}_{3}\right)_{4} \mathrm{NHCl}_{2}$ and $0.80 \%$ of $\left(\mathrm{CH}_{3}\right)_{4} \mathrm{NCl}$, assuming that both starting materials were pure. Keeping the sample under atmospheric pressure of gaseous hydrogen chloride for two weeks did not change the composition significantly. Handling of this compound was done in an anhydrous nitrogen atmosphere in order to prevent the absorption of moisture, and was minimized in order to avoid the change of composition by loss of hydrogen chloride as a consequence of its substantial dissociation pressure.

\section{Cryogenic Technique}

The heat capacity of tetramethylammonium hydrogen dichloride was measured in the Mark III cryostat, which is similar to the Mark II $^{13}$ in design except that it has no heat exchanger to precool the bundle of leads before it comes into contact with the liquid-helium tank.

Calorimeter W-9 was modified (thus becoming calorimeter $\mathrm{W}-9 \mathrm{~A}$ ) by soldering on a three-hole thermocouple well to accomodate a multijunction differential thermocouple to the middle portion of the adiabatic shield of the Mark III cryostat. The heat capacity of the empty calorimeter W-9A with the heater-thermometer assembly was therefore redetermined. It was then

${ }^{11}$ F. Kaufler and E. Kunz, Ber. deut. chem. Ges. 42, 385 (1909). 12 S. S. Chang and E. F. Westrum, Jr., J. Chem. Phys. 36, 2420 (1962).

${ }^{13}$ E. F. Westrum, and J. P. McCullough, "Thermodynamics of organic crystals," in Physics and Chemistry of the Organic Solid State, edited by D. Fox, M. M. Labes, and A. Weissberger [Interscience Publishers, Inc., New York (to be published)]. 
loaded with $33.712 \mathrm{~g}$ (in vacuo) of tetramethylammonium hydrogen dichloride and was sealed with $9.2 \mathrm{~cm} \mathrm{Hg}$ pressure of helium at $300^{\circ} \mathrm{K}$. The heat capacity of the empty calorimeter-heater-thermometer assembly represented from 30 to $20 \%$ of the total observed heat capacity from $5^{\circ}$ to $20^{\circ} \mathrm{K}$, increased to $50 \%$ at $100^{\circ} \mathrm{K}$, and decreased to $40 \%$ at $350^{\circ} \mathrm{K}$. A capsule-type platinum resistance thermometer of laboratory designation A-3 was used for the measurement of temperature.

The adiabatic shield was controlled manually below $100^{\circ} \mathrm{K}$; above this temperature the adiabatic shield was controlled automatically through electronic devices. The signal from the differential thermocouple between the calorimeter and the cylindrical portion of the adiabatic shield was fed into a Leeds \& Northrup dc microvolt amplifier serving as the preamplifier for the $L \& N$ Speedomax type $G$ recorder. The off-balance signal against the control point from the recorder was in turn fed into an $\mathrm{L} \& \mathrm{~N}$ current-adjusting type control chassis having proportional, rate-time, and reset controls. The control signal from the CAT unit, after being chopped, was amplified through a 20-w high-fidelity power amplifier to furnish the necessary energy to maintain the temperature of the adiabatic shield at the control point. The impedance of the output from the power amplifier was matched to an autotransformer (which permitted manual selection of power level); its secondary was connected to the shield heater. The bottom and top parts of the adiabatic shield were also controlled by similar channels, but the activating signals were derived from differential thermocouples between the particular part of the adiabatic shield and the cylindrical portion. The temperatures were usually controlled to within $0.002^{\circ} \mathrm{K}$, with momentary upsets of the order of less than $0.04^{\circ} \mathrm{K}$ caused by the start or termination of the energy input.

\section{Decomposition Pressure Measurements}

The decomposition pressure of tetramethylammonium hydrogen dichloride was first measured in an isoteniscope-like apparatus with mercury as the confining liquid. A capillary tube provided at the bottom of the $U$ tube of the isoteniscope was fitted with a stopcock leading to a reservoir in order to facilitate the filling and removal of the mercury. The acid salt was prepared in the sample tube in situ by reacting the neutral salt with hydrogen chloride as described before. After the system had been subjected to a high vacuum while the sample was kept at $0^{\circ} \mathrm{C}$, mercury was allowed to fill the $\mathrm{U}$ tube and equilibrium was established. The composition of the sample could be changed by first drawing off the confining mercury to the reservoir and then pumping off a certain amount of the vapor evolved. However, the results from these measurements were not very reproducible and showed a scattering of about $\pm 2 \%$ to the smooth curve as obtained by a later experiment described below. Since the vapor phase was composed mainly of hydrogen chloride, it was considered that some reaction
TABLE I. Heat capacity of tetramethylammonium hydrogen dichloride.

$\left[\left(\mathrm{CH}_{3}\right)_{4} \mathrm{NHCl}_{2}, 1\right.$ mole $=146.070 \mathrm{~g}$, in cal $\left.\mathrm{g} \mathrm{mole}^{-1}{ }^{\circ} \mathrm{K}^{-1}.\right]$

\begin{tabular}{|c|c|c|c|c|c|}
\hline$T,{ }^{\circ} \mathrm{K}$ & $C_{p}$ & $T,{ }^{\circ} \mathrm{K}$ & $C_{p}$ & $T,{ }^{\circ} \mathrm{K}$ & $C_{p}$ \\
\hline \multicolumn{2}{|c|}{ Series I } & 16.35 & 2.250 & 103.13 & 24.53 \\
\hline & & 18.04 & 2.897 & 111.45 & 25.83 \\
\hline \multirow[t]{2}{*}{128.72} & \multirow[t]{2}{*}{28.30} & 19.99 & 3.692 & \multirow{2}{*}{\multicolumn{2}{|c|}{ Series VI }} \\
\hline & & 21.94 & 4.521 & & \\
\hline \multicolumn{2}{|c|}{ Series II } & 24.46 & $\begin{array}{l}5.613 \\
6.860\end{array}$ & 11625 & 2640 \\
\hline 154.31 & 31.77 & $\begin{array}{l}21.39 \\
30.57\end{array}$ & $\begin{array}{l}6.869 \\
8.183\end{array}$ & $\begin{array}{l}116.25 \\
124.69\end{array}$ & 27.45 \\
\hline 162.91 & 32.87 & 33.84 & 9.470 & 132.84 & 28.89 \\
\hline 171.73 & 33.94 & 37.40 & 10.81 & 140.91 & 29.99 \\
\hline 180.52 & 34.98 & 41.34 & 12.03 & 149.24 & 31.11 \\
\hline 189.18 & 36.02 & 45.67 & 13.36 & & \\
\hline 197.83 & 37.04 & 50.49 & 14.67 & \multirow{2}{*}{\multicolumn{2}{|c|}{ Series VII }} \\
\hline 206.71 & 38.08 & 55.94 & 15.98 & & \\
\hline 215.75 & 39.12 & 61.95 & 17.32 & \multirow{3}{*}{$\begin{array}{l}228.99 \\
237.57 \\
245.99 \\
254.64 \\
263.66\end{array}$} & 40.65 \\
\hline 224.84 & 40.20 & 68.40 & 18.61 & & 41.64 \\
\hline \multicolumn{2}{|c|}{ Series III } & \multicolumn{2}{|c|}{ Series IV } & & $\begin{array}{l}42.09 \\
43.64\end{array}$ \\
\hline 5.82 & 0.069 & 70.35 & 18.93 & $\begin{array}{l}203.00 \\
272.80\end{array}$ & $\begin{array}{l}44.78 \\
45.90\end{array}$ \\
\hline 6.41 & 0.100 & 77.01 & 20.14 & 282.00 & 47.01 \\
\hline 7.19 & 0.148 & \multirow{3}{*}{\multicolumn{2}{|c|}{ Series V }} & 291.10 & 48.18 \\
\hline 8.08 & 0.232 & & & 299.96 & 49.27 \\
\hline 8.95 & 0.331 & & & 308.81 & 50.45 \\
\hline 9.87 & 0.465 & 73.59 & 19.50 & 317.62 & 51.65 \\
\hline 10.94 & 0.664 & 80.38 & 20.78 & 326.67 & 52.97 \\
\hline 12.18 & 0.940 & 87.52 & 22.11 & 335.81 & 54.64 \\
\hline 13.49 & 1.300 & 95.09 & 23.27 & 344.86 & 56.29 \\
\hline 14.86 & 1.728 & & & & \\
\hline
\end{tabular}

might have occurred between the vapor and mercury and thus caused the low reproducibility by contaminating the glass-mercury interface of the manometer.

Because of the corrosive properties of hydrogen chloride, a sickle-shaped Bourdon gauge made of Pyrex glass with its pointer connected to a lever amplification system $^{14}$ was used as the null indicator. Sensitivity of this gauge was about $5 \mathrm{~mm} \mathrm{Hg}$ for a 1-mm deflection of the sharp pointer of the mechanical lever. With a $10 \mathrm{X}$ telescope, a pressure difference of $0.1 \mathrm{~mm} \mathrm{Hg}$ could be easily detected. The reproducibility of the gauge was believed to be within a pressure of $0.3 \mathrm{~mm} \mathrm{Hg}$. The envelope of this gauge was wrapped with aluminum foil, wound around with heating tape, and then insulated with asbestos sheets. It was kept continuously at a temperature of about $150^{\circ} \mathrm{C}$. The sealed sample tube assembly was immersed in an oil bath. The temperature of the Finol (oil) bath was controlled by a mercury thermoregulator in connection with a sensitive dcoperated relay and manually adjusted heaters controlled by autotransformers. The temperature of the bath was made uniform through turbulent stirring and the fluctuation in temperature at the sample container was less than $0.05^{\circ} \mathrm{C}$.

The sample used was transferred to the apparatus from the bulk of the calorimetric sample in the dry box with an anhydrous-nitrogen atmosphere. The sample tube of the Bourdon-gauge assembly was provided with

\footnotetext{
${ }^{14}$ S. G. Foord, J. Sci. Instr. 11, 126 (1934).
} 
TABLE II. Thermodynamic properties of tetramethylammonium hydrogen dichloride.

[In units of cal, mole, ${ }^{\circ} \mathrm{K}$; $\left(\mathrm{CH}_{3}\right)_{4} \mathrm{NHCl}_{2}, 1$ mole $=146.070 \mathrm{~g}$.]

\begin{tabular}{rrrrr}
\hline \hline$T$ & $C_{p}$ & $S^{\circ}$ & $H^{\circ}-H_{0}{ }^{\circ}$ & $-\left(F^{\circ}-H_{0}{ }^{\circ}\right) / T$ \\
\hline 5 & 0.039 & 0.014 & 0.051 & 0.003 \\
10 & 0.488 & 0.139 & 1.075 & 0.031 \\
15 & 1.774 & 0.552 & 6.382 & 0.126 \\
20 & 3.697 & 1.315 & 19.89 & 0.321 \\
25 & 5.848 & 2.370 & 43.73 & 0.621 \\
30 & 7.957 & 3.625 & 78.28 & 1.015 \\
35 & 9.907 & 5.000 & 123.02 & 1.485 \\
40 & 11.65 & 6.439 & 176.99 & 2.014 \\
45 & 13.18 & 7.901 & 239.14 & 2.587 \\
50 & 14.54 & 9.361 & 308.50 & 3.191 \\
60 & 16.87 & 12.225 & 465.9 & 4.460 \\
70 & 18.89 & 14.980 & 644.9 & 5.767 \\
80 & 20.72 & 17.623 & 843.0 & 7.085 \\
90 & 22.44 & 20.163 & 1058.9 & 8.398 \\
100 & 24.05 & 22.612 & 1291.4 & 9.680 \\
110 & 25.59 & 24.977 & 1539.7 & 10.980 \\
120 & 27.07 & 27.268 & 1803.1 & 12.242 \\
130 & 28.49 & 29.491 & 2080.9 & 13.484 \\
140 & 29.87 & 31.653 & 2372.7 & 14.705 \\
150 & 31.20 & 33.759 & 2678.1 & 15.905 \\
160 & 32.49 & 35.815 & 2996.6 & 17.085 \\
170 & 33.74 & 37.822 & 3327.8 & 18.246 \\
180 & 34.94 & 39.784 & 3671.2 & 19.389 \\
190 & 36.12 & 41.705 & 4026.5 & 20.513 \\
200 & 37.28 & 43.587 & 4393.6 & 21.620 \\
210 & 38.45 & 45.435 & 4772.2 & 22.710 \\
220 & 39.61 & 47.250 & 5162.5 & 23.784 \\
230 & 40.78 & 49.037 & 5564.5 & 24.843 \\
240 & 41.95 & 50.797 & 5978.2 & 25.888 \\
250 & 43.13 & 52.534 & 6403.6 & 26.919 \\
260 & 44.32 & 54.249 & 6840.8 & 27.938 \\
270 & 45.53 & 55.944 & 7290.1 & 28.944 \\
280 & 46.77 & 57.622 & 7751.6 & 29.938 \\
290 & 48.04 & 59.285 & 8225.6 & 30.921 \\
300 & 49.31 & 60.935 & 8712.3 & 31.894 \\
350 & 57.35 & 69.090 & 11359.3 & 36.625 \\
273.15 & 45.92 & 56.47 & 7434 & 29.26 \\
298.15 & 49.07 & 60.63 & 8621 & 31.72 \\
\hline \hline
\end{tabular}

breakoff seals and parallel-connecting-tube assemblies between the side tube and the vacuum manifold to facilitate later evacuation of the evolved vapor and thus change the composition of the system. After the gauge was pumped down and then filled with dry helium, the breakoff seal in the sample tube was cracked by actuating a glass-sealed iron plunger with a magnet. The sample was then cooled in a mixture of dry ice and denatured alcohol, and subjected to a high vacuum. The parallel-connecting tube between the manifold and the side tube was then sealed off. This seal was placed below the surface of the oil bath in order to assure that there was no cold spot in the whole system. The measurements were then begun for the original composition of the sample. The composition of the sample was varied by opening the breakoff seal beside the sealed parallel tube and between the manifold and the side tube of the sample tube. After a certain amount of vapor had been pumped off, the side tube was sealed and measurements on the second composition could be made. The composition could be varied as many times as these breakoff seals and parallel-connecting-tube assemblies permitted.

Bath temperatures were measured by means of a thermometer which had been calibrated by the National Bureau of Standards with corrections for exposed stem. The pressure was measured by means of a mercury manometer $1 \mathrm{~cm}$ in diameter. Meniscus corrections were not applied, but the height of the mercury columns were corrected to the density of mercury at $0^{\circ} \mathrm{C}$ and to standard gravity.

\section{CALORIMETRIC RESULTS}

The experimental heat-capacity determination for the two compounds are listed in Table $\mathrm{I}$ in chronological order in terms of the thermochemical calorie defined as 4.1840 abs $j$. The ice point is taken as $273.15^{\circ} \mathrm{K}$. An analytically determined curvature correction ${ }^{13}$ was applied to the observed values of $\Delta H / \Delta T$. The approximate temperature increments usually can be inferred from the adjacent mean temperatures in Table I. Molal values of the heat capacities at constant pressure, the entropies, the enthalpy increments, and the free-energy functions are listed at selected rounded temperatures in Table II. These values were obtained from a smooth curve fit by least squares to the experimental data by means of a digital computer or by appropriate integration based on the curve. The reported values of the heatcapacity data are believed to have probable errors less

TABLE III. Decomposition pressure measurements on tetramethylammonium hydrogen dichloride in chronological sequence.

\begin{tabular}{ccccc}
\hline$T,{ }^{\circ} \mathrm{K}$ & $P, \mathrm{~mm} \mathrm{Hg}$ & $t_{T},{ }^{\mathrm{a}} \mathrm{hr}$ & $t_{e},{ }^{\mathrm{b}} \mathrm{hr}$ & Method $^{\mathrm{m}}$ \\
\hline
\end{tabular}

Series I; $99.2 \%\left(\mathrm{CH}_{3}\right)_{4} \mathrm{NHCl}_{2}$ [calorimetric sample]

$\begin{array}{lrrrc}372.87 & 187.0 & 21 & 10 & h \\ 357.12 & 95.1 & 25 & 10 & h \\ 347.71 & 60.1 & 26 & 8 & h, l \\ 352.63 & 76.8 & 24 & 10 & h, l \\ 361.04 & 112.7 & 12 & 8 & h \\ 365.43 & 136.8 & 13 & 9 & h \\ 372.72 & 185.1 & 7 & 5 & l \\ 365.41 & 135.6 & 16 & 10 & h, l \\ 348.20 & 61.7 & 95 & 80 & h, l \\ 358.15 & 99.5 & 22 & 18 & h \\ 367.13 & 140.6 & 100 & 95 & l \\ 372.06 & 176.4 & 56 & 50 & h, l \\ 378.32 & 229.8 & 24 & 18 & l \\ 363.16 & 123.7 & 22 & 14 & h, l\end{array}$

Series II; About $60 \%\left(\mathrm{CH}_{3}\right)_{4} \mathrm{NHCl}_{2}$ and $40 \%\left(\mathrm{CH}_{3}\right)_{4} \mathrm{NCl}$

$\begin{array}{lrrrr}364.54 & 128.3 & 22 & 8 & h \\ 360.23 & 106.9 & 25 & 15 & h \\ 343.96 & 49.9 & 48 & 30 & h \\ 338.77 & 39.0 & 50 & 30 & h\end{array}$

\footnotetext{
${ }^{t} \boldsymbol{T}$ signifies total time of observation after reaching temperature $T$.

b $t_{e}$ signifies time during which pressure was observed to be substantially at equilibrium value.

c Method: $h$ signifies equilibrium approached from higher pressures and temperatures and $l$ from lower pressures and temperatures.
} 
than $0.1 \%$ at temperatures above $25^{\circ} \mathrm{K}$, about $1 \%$ at $10^{\circ} \mathrm{K}$, and $5 \%$ at $5^{\circ} \mathrm{K}$. The probable errors of the thermodynamic functions are considered to be less than $0.1 \%$ above $100^{\circ} \mathrm{K}$.

No thermal anomaly was found from $5^{\circ}$ to $350^{\circ} \mathrm{K}$ by these calorimetric studies, nor has differential thermal analysis extended to about $150^{\circ} \mathrm{C}$ revealed any thermal anomaly. Unlike that of the neutral salt, ${ }^{12}$ the slope of the heat capacity of the acid salt increases markedly in the region above $300^{\circ} \mathrm{K}$. Heat-capacity values listed in Table I have been corrected for the decomposition at temperatures above $250^{\circ} \mathrm{K}$ by means of the decomposition pressure data and the enthalpy of reaction obtained by direct equilibrium measurements. The correction term is less than $0.01 \%$ at $250^{\circ} \mathrm{K}$, is $0.1 \%$ at about $300^{\circ} \mathrm{K}$, and about $0.6 \%$ at about $350^{\circ} \mathrm{K}$.

Assuming that tetramethylammonium hydrogen dichloride was prepared from very pure starting materials and that there is no solid solution formed, then the true molal heat capacity of the acid salt $C_{1}$ would be obtained from the apparent molal heat capacity of the acid salt $C_{1}{ }^{*}$ (calculated upon the assumption that the sample was pure acid salt) by the following equation:

$$
C_{1}=C_{1}{ }^{*}+[(1-a) / a]\left[C_{1}{ }^{*}-\left(M W_{1} / M W_{2}\right) C_{2}\right],
$$

where $a$ is the fraction in weight of the acid salt in the sample, $C_{2}$ the molal heat capacity of the neutral salt, and $M W_{1}$ and $M W_{2}$ the molecular weight of the acid and neutral salt respectively. The correction term is about $+0.2 \%$ in the temperature range from $5^{\circ}$ to $30^{\circ} \mathrm{K}$, and then decreases to $0.0 \%$ at $80^{\circ} \mathrm{K}$, and to less than $-0.02 \%$ above $80^{\circ} \mathrm{K}$. Hence, the correction has not been applied to the apparent molal heat capacity reported in Table I.

\section{RESULTS OF DECOMPOSITION PRESSURE MEASUREMENTS}

Decomposition pressure of tetramethylammonium hydrogen dichloride was determined from $65^{\circ}$ to $105^{\circ} \mathrm{C}$ for the original composition (99.2\%) and for a composition of approximately $60 \%\left(\mathrm{CH}_{3}\right)_{4} \mathrm{NHCl}_{2}$. Since the results from these two compositions lie on the same pressure-vs-temperature curve, probability of formation of solid solution is very remote. Results of the decomposition pressure measurement are listed in Table III in chronological order and are shown in Fig. 1. The probable error in the temperature measurement is believed to be less than $0.1^{\circ} \mathrm{C}$; hence the uncertainty in pressure caused by the error in temperature is in the order of $1 \mathrm{~mm} \mathrm{Hg}$ at about $100^{\circ} \mathrm{C}$, and about $0.1 \mathrm{~mm}$ $\mathrm{Hg}$ at about $70^{\circ} \mathrm{C}$. However, at temperatures near $70^{\circ} \mathrm{C}$ reproducibility is lower than that expected from the uncertainty in the temperature measurement because of the lack of precision of the Bourdon gauge used was of the order of $0.3 \mathrm{~mm} \mathrm{Hg}$, and presumably by the slower equilibrium process, with probably a higher absorption and lower diffusivity of hydrogen chloride

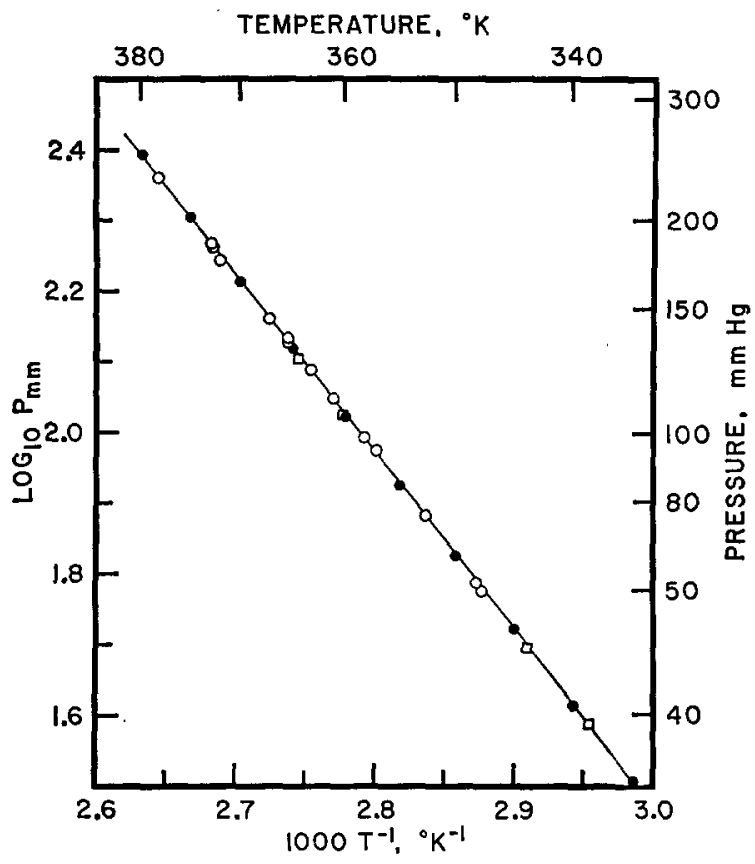

FIG. 1. Decomposition pressure of tetramethylammonium hy. drogen dichloride. Series I observations (O), Series II observations $(\square)$, and calculated values $(\bigcirc)$.

at lower temperatures. The rate of establishment of pressure equilibrium in this system is rather slow, 10 to $20 \mathrm{hr}$ are typical time increments required to detect appreciable pressure increments. Points were obtained by approaching equilibrium both from higher and from lower temperatures and pressures. The time dependence of two typical decomposition pressure measurements are presented in the dissertation. ${ }^{15}$

The equation for the equilibrium decomposition pressure was obtained with the aid of the differential heat capacity of the reaction, $\Delta C_{p}=30.803-0.11215 T$ cal mole ${ }^{-1}{ }^{\circ} \mathrm{K}^{-1}$ from the range $330^{\circ}$ to $380^{\circ} \mathrm{K}$, obtained by extrapolating the heat-capacity determinations for the acid and the neutral salts to slightly higher temperature and by computed heat capacities for hydrogen chloride from molecular data. ${ }^{16}$ This equation, $\log _{10} P_{\mathrm{mm}}=$ $-28.4677-1698.5 T^{-1}+15.502 \log _{10} T-0.012256 T$, accords with the experimental data within 0.003 in units of $\log _{10} P_{\mathrm{mm}}$, or about $1.5 \mathrm{~mm} \mathrm{Hg}$ at about $100^{\circ} \mathrm{C}$ and less at lower temperatures. Decomposition pressures are calculated at $5^{\circ}$ intervals from $335^{\circ}$ to $380^{\circ} \mathrm{K}$ and are presented together with the experimental values in Fig. 1. Extrapolation of the equation indicates the pressures to be $1.8 \mathrm{~mm} \mathrm{Hg}$ at $298.15^{\circ} \mathrm{K}$ and $760 \mathrm{~mm} \mathrm{Hg}$ at $410.8^{\circ} \mathrm{K}$.

${ }^{15}$ S. S. Chang, Cryogenic Thermodynamic Studies on Some Globular Molecules and on the System $\mathrm{Me}_{4} \mathrm{NCl}-\mathrm{Me}_{4} \mathrm{NHCl}$, University Microfilms, Ann Arbor, Michigan (1962).

${ }_{10}$ Selected Values of Chemical Thermodynamic Properties, National Bureau of Standards, Circular 500, Washington, D. C. (1952). 


\section{DISCUSSION}

\section{Equilibrium Constant}

Dissociation of tetramethylammonium hydrogen dichloride into the neutral salt and hydrogen chloride,

$$
\left(\mathrm{CH}_{3}\right)_{4} \mathrm{NHCl}_{2}=\left(\mathrm{CH}_{3}\right)_{4} \mathrm{NCl}+\mathrm{HCl} \text {, }
$$

may involve complicating reactions at higher temperatures, e.g., further dissociation of tetramethylammonium chloride into trimethylamine and chloromethane:

$$
\left(\mathrm{CH}_{3}\right)_{4} \mathrm{NCl}=\left(\mathrm{CH}_{3}\right)_{3} \mathrm{~N}+\mathrm{CH}_{3} \mathrm{Cl} \text {. }
$$

Recombination of hydrogen chloride and trimethylamine to form trimethylamine hydrochloride is thus possible:

$$
\left(\mathrm{CH}_{3}\right)_{3} \mathrm{~N}+\mathrm{HCl}=\left(\mathrm{CH}_{3}\right)_{3} \mathrm{NHCl} \text {. }
$$

Further reaction of trimethylamine hydrochloride with hydrogen chloride to give dihydrochloride

$$
\left(\mathrm{CH}_{3}\right)_{3} \mathrm{NHCl}+\mathrm{HCl}=\left(\mathrm{CH}_{3}\right)_{3} \mathrm{~N} \cdot 2 \mathrm{HCl} \text {, }
$$

is less likely due to the low stability of the dihydrochloride at room temperature..$^{17}$ However, at elevated temperatures, trimethylamine hydrochloride may react with hydrogen chloride to give lower amine hydrochlorides and chloromethane; e.g., $\left(\mathrm{CH}_{3}\right)_{3} \mathrm{NHCl}+\mathrm{HCl}=$ $\left(\mathrm{CH}_{3}\right)_{2} \mathrm{NH}_{2} \mathrm{Cl}+\mathrm{CH}_{3} \mathrm{Cl}$, and eventually yielding ammonium chloride and chloromethane: $\left(\mathrm{CH}_{3}\right)_{3} \mathrm{NHCl}+$ $3 \mathrm{HCl}=\mathrm{NH}_{4} \mathrm{Cl}+3 \mathrm{CH}_{3} \mathrm{Cl}$.

Considering the equilibria among reactions (1), (2), and (3) only, we conclude that reaction (3) would occur only if $K_{3} \leq K_{1} K_{2}{ }^{\frac{1}{3}}$ in which the $K^{\prime}$ 's represent the respective dissociation constants.

The decomposition pressure of tetramethylammonium chloride has been determined from $458^{\circ}$ to $503^{\circ} \mathrm{K}$ by Smith and Calvert. ${ }^{18}$ Since their pressure-vs-temperature relation has a minimum in pressure at about $413^{\circ} \mathrm{K}$, it is not suitable for extrapolation to lower temperatures. By fitting their data to an equation of the form $\log _{10} P_{\mathrm{mm}}=A+B T^{-1}$, the coefficients $A=11.066$ and $B=-4165.4$ are obtained. Extrapolation with this equation leads to a pressure of $0.8 \mathrm{~mm} \mathrm{Hg}$ at $373^{\circ} \mathrm{K}$.

Within the temperature range of the present decomposition pressure measurements on tetramethylammonium hydrogen dichloride, reaction (1) predominates, and the vapor phase can be viewed as composed almost entirely of hydrogen chloride, due to the very low decomposition pressure of the neutral salt and its slowness in reaching equilibrium at these temperatures. Hence, $K_{1}$ is approximately equal to the observed decomposition pressure of tetramethylammonium hydrogen dichloride, of which, for example, the value at $373^{\circ} \mathrm{K}$ is $191 \mathrm{~mm} \mathrm{Hg}$. The value of $K_{2}$ at the same temperature can be calculated from the above extrapolated equilibrium decomposition data as 0.16 with pressures ex-

\footnotetext{
${ }^{17}$ F. Ephraim, Ber. deut. chem. Ges. 47, 1842 (1914).

${ }_{18}$ A. Smith and R. P. Calvert, J. Am. Chem. Soc. 36, 1363 (1914).
}

pressed in $\mathrm{mm} \mathrm{Hg}$. Hence the decomposition pressure of trimethylamine hydrochloride, $2 K_{3^{3}}{ }^{3}$, must be less than $17.5 \mathrm{~mm} \mathrm{Hg}$ in order that this compound would be formed during the equilibrium process.

No appreciable decomposition pressure (i.e., not in excess of $1 \mathrm{~mm} \mathrm{Hg}$ ) was detected for trimethylamine hydrochloride by heating up to $403^{\circ} \mathrm{K}$ for $24 \mathrm{hr}$ in an isoteniscope-type apparatus with mercury as the confining liquid as found in this research. However it has been reported ${ }^{19}$ that trimethylamine hydrochloride sublimes above $473^{\circ} \mathrm{K}$ and decomposes above $558^{\circ} \mathrm{K}$. Although the statements do not explicitly indicate whether the sublimation took place in air at atmospheric pressure or in vacuum, presumably the former is to be understood. Hence its decomposition equilibrium constant is comparable to that of tetramethylammonium chloride, and it would be formed eventually if the system is allowed to reach equilibrium. In this case, adjustments would need to be applied to the observed total decomposition pressure of the acid salt in order to compute the values of $K_{1}$, and precise low-pressure measurements would be needed of the equilibrium constants for the neutral salt and for trimethylamine hydrochloride in the temperature range investigated for the acid salt in order to minimize the error in making such large adjustments.

However, the foregoing treatments are unnecessary, since tetramethylammonium chloride is but slightly decomposed at the temperature of the measurement and the effect may be neglected since the time required to measure the equilibrium pressure of the acid salt at temperatures below $100^{\circ} \mathrm{C}$ is inadequate for equilibrium in reaction (2).

The rate of decomposition of the neutral salt has been reported ${ }^{17}$ to be very slow even at $518^{\circ} \mathrm{K}$. The pressure was said to reach only $182 \mathrm{~mm} \mathrm{Hg}$ during the first hour, although the extrapolated equilibrium pressure for this temperature is about $1060 \mathrm{~mm} \mathrm{Hg}$. Since the rate of

TABLE IV. Observations on the rate of decomposition of tetramethylammonium chloride.

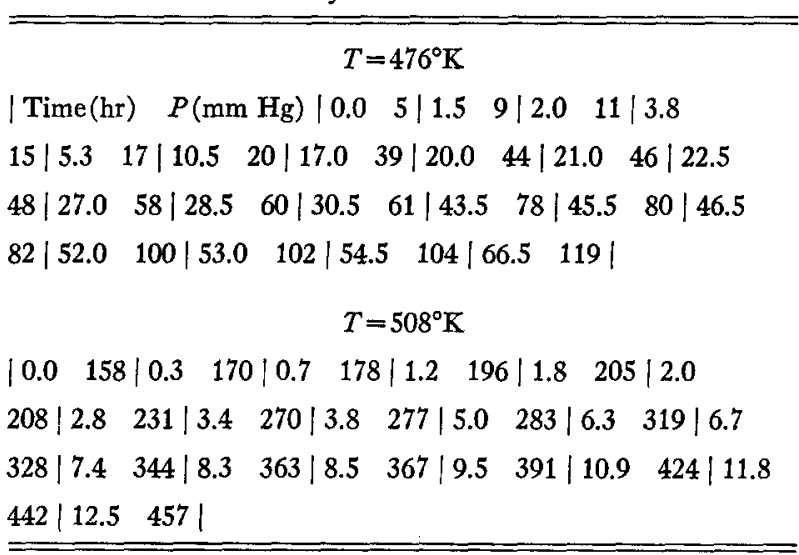

${ }^{19}$ M. C. Vincent, Compt. rend. 84, 1139 (1877) ; ibid. 85, 667 (1878); M. Delépine, Ann. chim. et phys. [7] 8, 451 (1896). 
TABLE V. Comparison of standard entropy changes for the reaction $\left(\mathrm{CH}_{3}\right)_{4} \mathrm{NHCl}_{2}=\left(\mathrm{CH}_{3}\right)_{4} \mathrm{NCl}+\mathrm{HCl}$.

\begin{tabular}{cllc}
\hline$T,{ }^{\circ} \mathrm{K}$ & \multicolumn{1}{c}{$\Delta S_{\mathrm{III}}{ }^{\circ}$} & \multicolumn{1}{c}{$\Delta S_{\mathrm{eq}}{ }^{\circ}$} & $\Delta S_{\mathrm{III}}{ }^{\circ}-\Delta S_{\mathrm{ec}}{ }^{\circ}$ \\
\hline 340 & $28.83 \pm 0.03$ & $28.79 \pm 0.10$ & 0.04 \\
350 & 28.60 & 28.56 & 0.04 \\
360 & 28.36 & 28.31 & 0.05 \\
370 & 28.08 & 28.03 & 0.05 \\
380 & 27.80 & 27.74 & 0.06 \\
\hline
\end{tabular}

reaction is often strongly influenced by temperature, it is reasonable to assume that the rate of decomposition at $373^{\circ} \mathrm{K}$ is extremely slow. In order to quantitatively verify this hypothesis, measurements on the rate of decomposition of the neutral salt at $476^{\circ}$ and $508^{\circ} \mathrm{K}$ were made by means of a Bourdon gauge similar in design and volume to that used for the acid salt. The results are presented in Table IV. The equilibrium decomposition pressures are in approximate accord with those reported. ${ }^{17}$ The rate of decomposition under the experimental conditions is found to be almost constant until about $\frac{1}{2}$ or $\frac{2}{3}$ of the equilibrium value is reached; the rate being about $25 \mathrm{~mm} \mathrm{Hg} / \mathrm{hr}$ at $508^{\circ} \mathrm{K}$ and $1.5 \mathrm{~mm} \mathrm{Hg} / \mathrm{hr}$ at $476^{\circ} \mathrm{K}$. In the closed system the pressure is directly proportional to the amount of the solid decomposed and the apparent rate far from equilibrium is substantially constant. If an Arrhenius relationship for the apparent rate is assumed, the extrapolated apparent rate of decomposition at $373^{\circ} \mathrm{K}$ on the basis of the data in Table IV is about $10^{-5} \mathrm{~mm} \mathrm{Hg} /$ $\mathrm{hr}$ for conditions similar to those in the measurement of the decomposition of the acid salt. Hence decomposition of the neutral salt would be negligibly small even after a month at $373^{\circ} \mathrm{K}$. Since all the other reactions indicated depend on the products of the decomposition of the neutral salt, reaction (2), these can also be neglected. Thus the observed total equilibrium pressure of the acid salt is considered to be due exclusively to hydrogen chloride from the decomposition of the acid salt alone-i.e., reaction (1).

\section{Evaluation of Residual Entropy}

Values of standard entropy changes for the decomposition of tetramethylammonium hydrogen dichloride into tetramethylammonium chloride and hydrogen chloride, reaction (1), from two sources are listed and compared in Table V. $S_{\text {eq }}^{\circ}$ represents the value derived from direct equilibrium measurements as $-\left[\partial\left(\Delta F^{\circ}\right) / \partial T\right]_{p}$, where $\Delta F^{\circ}=-R T \ln K_{p}=-R T \ln P$. The equilibrium decomposition pressure is considered to be identical with the equilibrium constant in this experiment on the basis that no solid solutions are formed and affect the activity of the solid and that the fugacity of hydrogen chloride is identical, within experimental error, to the pressure. If a Berthelot equation of state is assumed for hydrogen chloride, the activity coefficient $\gamma$ can be calculated by the following relationship:

$$
\ln \gamma=\ln (f / p)=\frac{9}{128}(\pi / \theta)\left[1-\left(6 / \theta^{2}\right)\right],
$$

in which $\pi$ and $\theta$ represent the reduced pressure and temperature, respectively. By taking the critical pressure and temperature of hydrogen chloride as $81.6 \mathrm{~atm}$ and $324.7^{\circ} \mathrm{K}, \gamma$ is found at $200 \mathrm{~mm} \mathrm{Hg}$ and $100^{\circ} \mathrm{C}$ to be 0.9993, which is almost unity. The probable errors noted are based upon the uncertainties in temperature of $0.1^{\circ}$ and in pressure as $0.5 \mathrm{~mm} \mathrm{Hg} . \Delta S^{\circ}{ }_{\text {III }}$ denotes the entropy change of the reaction as calculated from the third law entropies of the reactant and products involved. The entropy of hydrogen chloride gas was obtained from statistically calculated values ${ }^{16}$ and interpolated to the particular temperatures by taking the mean heat capacity of hydrogen chloride gas from $300^{\circ}$ to $400^{\circ} \mathrm{K}$ as $6.964 \pm 0.005 \mathrm{cal}^{\circ} \mathrm{K}^{-1} \mathrm{~mole}^{-1}$. The entropy values of the neutral ${ }^{12}$ and of the acid salts are obtained from work in this laboratory and from Table II, respectively. For the higher temperatures, slight extrapolations are involved.

Deviation of $\Delta S^{\circ}$ III from $\Delta S_{\text {eq }}^{\circ}$ is in general within $0.1 \mathrm{cal}^{\circ} \mathrm{K}^{-1} \mathrm{~mole}^{-1}$ as can be seen in the column $\Delta$ of Table $\mathrm{V}$. The agreement is considered good and without significant trend especially because of the use of some extrapolated entropy values for the neutral and the acid salts and because of the rather complicated nature of the decomposition reaction.

With the reasonable (and experimentally consistent) assumptions that tetramethylammonium chloride and hydrogen chloride are perfectly crystalline substances at very low temperatures, that neither solid solutions nor fractional hydrochlorides occur over the temperature and composition ranges studied and that the $[\mathrm{Cl}-\mathrm{H}-\mathrm{Cl}]$ - ion is symmetrically situated, this finding of a virtually zero residual entropy in the acid salt confirms the existence of a symmetrical $[\mathrm{Cl}-\mathrm{H}-\mathrm{Cl}]-$ ion with a single minimum potential-energy function. This conclusion is consistent with the great similarity of the infrared spectra of the $[\mathrm{Cl}-\mathrm{H}-\mathrm{Cl}]^{-}$ion and the $[\mathrm{F}-\mathrm{H}-\mathrm{F}]-$ ion reported by Waddington. ${ }^{9}$ Diffraction studies of the crystal structure of tetramethylammonium hydrogen dichloride are an obvious desideratum.

\section{ACKNOWLEDGMENTS}

The partial support of the Division of Research of the United States Atomic Energy Commission is gratefully acknowledged. One of us (S. S. C.) is indebted to the University of Michigan for the award of a John Jacobson Scholarship and a Mary F. Stevens Fellowship. 